\title{
Mathematical modelling using response surface methodology for optimization of the operating conditions for esteramine production aided by solid catalyst
}

\author{
Haliza A. Aziz ${ }^{1}$, Mohamed K. Aroua ${ }^{2}$, Rozita Yusoff², Noor A. Abas ${ }^{1}$, Zainab Idris ${ }^{1}$, Hazimah A. \\ Hsassan $^{1}$ \\ ${ }^{1}$ Advanced Oleochemical Technology Division, Malaysian Palm Oil Board,43000, Kajang, \\ Selangor, Malaysia \\ ${ }^{2}$ Department of Chemical Engineering, Faculty of Engineering, University of Malaya,50603, Kuala \\ Lumpur, Malaysia
}

Email: liza_azi@mpob.gov.my

\begin{abstract}
This study involved optimization of the transesterification of palm-based methyl palmitate with triethanolamine to form esteramine, an intermediate for esterquats. This reaction is aided by $\mathrm{Ca}-\mathrm{Al}$ as a heterogeneous catalyst and conducted in a 500-ml reaction unit. Response surface methodology (RSM) in combination with face-centered design was used to optimize the operating parameters. Results show that temperature was the most significant variable affecting the conversion of methyl palmitate, followed by catalyst dosage, quadratic effect of catalyst dosage, vacuum and interaction of vacuum and catalyst dosage. The optimum reaction conditions obtained were at temperature of $169{ }^{\circ} \mathrm{C}$, catalyst dosage of $0.78 \%$ and vacuum of 299 mbar. The optimized operating conditions could be used to further improve the selectivity that would maximize the formation of di-esteramine and minimize the tri-esteramine content by improving the $\mathrm{Ca}-\mathrm{Al}$ catalyst basicity and acidity ratio.
\end{abstract}

Keywords: Esteramine, Transesterification, Methyl Palmitate, Heterogeneous Catalyst, Esterquats.

\section{INTRODUCTION}

With an excellant environmental profile and the good softening effect of the esterquats have made this surfactant a better replacement for the conventional distearyl dimethyl ammonium compounds as an active ingredient in fabric softeners. Esterquats is an interesting class of quaternaries, which are characterized by the presence of hydrophobic alkyl chains that link to the positively charged nitrogen molecule via ester bonds. The presence of this ester link will provide easy hydrolysis into fatty acids and short chain quats [2-3]. Generally, esterquats are produced via a two-stage process in which, triethanolamine is first esterified with fatty acid in the presence of homogeneous acid catalyst or transesterified with ester using a base catalysts to produce the desired esteramine. Esteramine, which consists of mixtures of mono, di and triesteramine is then quaternized with methylating agent to introduce a positive charge onto the esterquats molecule. Optimization of the esterification or transesterification process for maximum conversion into esteramine is the key step in the preparation of esterquats. However, homogeneous catalysts employed in the process are difficult to be separated from the product [4]. Besides, homogeneous acid catalysts such as hypophosphorous acid, para-toluenesulfonic acid and sulfuric acid are toxic and corrosive, while sodium methoxide used in transesterification process can be a serious health hazard to humans upon contact. These homogeneous catalysts are also not reusable. Furthermore, the use of freshly prepared $1 \%$ sodium methoxide solution as catalyst in previous transesterification process [5-6] will not be economical for industrial scale esteramine production. Due to these limitations, heterogeneous catalysts have been proposed as alternative to the homogeneous catalysts for the production of esteramine.

Direct esterification of fatty acids via heterogeneous catalysis for esteramine production was reported in several literatures. Lipase-catalyzed esterification of oleic acid and triethanolamine for esteramine production was reported and response surface methodology (RSM) was used to optimize the enzymatic process conditions. The optimum conditions were established at enzyme amount of $4.77 \%$, reaction time of $24 \mathrm{~h}$, temperature of $61.9^{\circ} \mathrm{C}$, mole ratio of 1,1 (oleic acid to triethanolamine) and agitation speed of $480 \mathrm{rpm}$ with the highest conversion of $63.57 \%$ obtained [7]. Esterification between stearic acid and triethanolamine to produce triethanolamine ester employing solid catalysts such as zirconium sulfate supported on MCM-41, SBA-15 with pore diameter 6 and $9 \mathrm{~nm}$ as well as aluminium supported on SBA15 mesoporous molecular sieves have been reported $[8,9,10]$. The optimum operating conditions for esterification of stearic 
acid and triethanolamine aided by these solid acid catalysts were reported at temperature of $190{ }^{\circ} \mathrm{C}$, catalyst dosage of $0.25 \%$, mole ratio of $1.8,1$ of stearic acid to triethanolamine and $6 \mathrm{~h}$ reaction time.

Production of esteramine from a novel heterogeneous transesterification process of palm-based methyl palmitate and triethanolamine has been explored in which, $\mathrm{Ca}-\mathrm{Al}$ catalyst, a hydrotalcite-like compounds (HTLC) was employed [11]. This catalyst was chosen as it could be derived from a cheap source of calcium nitrate and aluminum nitrate. Furthermore, HTLC shows several advantages over other heterogeneous catalyst such as high dispersion of active sites, high thermal stability and large surface area [12]. The $\mathrm{Ca}-\mathrm{Al}$ catalyst has been used in transesterification of soybean oil in methanol and ethanol to produce biodiesel [13]. The highest conversion of soybean oil was $94 \%$ with ethanol and $100 \%$ with methanol when the transesterification was performed at temperature $68.5{ }^{\circ} \mathrm{C}$ (methanol) and $78.5{ }^{\circ} \mathrm{C}$ (ethanol) and mole ratio of 1 to 30 (oil/alcohol). KF/Ca-Al hydrotalcite-like compounds was also employed as solid base catalyst in the transesterification of methanol with palm oil to produce biodiesel. For the mass ratio 80 wt.\% (KF. $6 \mathrm{H}_{2} \mathrm{O}$ to $\mathrm{Ca}-\mathrm{Al}$ mixed-oxides) catalyst, under the optimal condition at $65^{\circ} \mathrm{C}, 5 \%$ catalyst, methanol to oil molar ratio of 12,1 and $5 \mathrm{~h}$ reaction time, the highest biodiesel yield obtained was $97.98 \%$ [14].

In our previous study [11], effect of reaction temperature, vacuum, catalyst dosage and agitator speed on the conversion of methyl palmitate into esteramine was investigated via heterogeneous transesterification. However, the work did not include any possible interaction effect between each of these reaction parameters as the optimization involved changing the value of one reaction parameter at a time for each experiment, while keeping the others at fixed level. This technique also known as one-factor-at-a-time (OFAT) experimental approach [15]. Under this approach, simultaneous influence of all the factors was poorly understood. Moreover, OFAT optimization process is time-consuming due to large number of experiments required for the study. The optimum operating conditions established in previous work using OFAT approach, consisting of a mole ratio of 1.8,1 (methyl palmitate, triethanolamine), $170{ }^{\circ} \mathrm{C}, 10 \mathrm{mbar}, 0.5 \%$ catalyst dosage and duration of $2 \mathrm{~h}$, which converted the methyl palmitate at $98 \%$, yielding $23.50 \%$ mono, $47.0 \%$ di and $23.90 \%$ tri-esteramine. Therefore, the investigation on interaction effects among the process variables towards conversion and optimization of the operating conditions using multivariate statistic technique in the transesterification of methyl palmitate and triethanolamine aided by $\mathrm{Ca}-\mathrm{Al}$ solid catalyst for esteramine production were carried out. Facecentered cube design was used to design the experiment and RSM was performed for the process optimization. A mathematical model was generated to demonstrate the relationship between the operating parameters and conversion of methyl palmitate. Reusability of $\mathrm{Ca}-\mathrm{Al}$ catalyst was evaluated and the morphology of the catalyst was determined using scanning electron microscopy (SEM) .

\section{EXPERIMENTAL}

\subsection{Materials}

Palm-based methyl palmitate (purity, $98 \%$ ) was purchased from Carotino Sdn Bhd and triethanolamine (purity, $99 \%$ ) was purchased from Fisher Scientific (M) Sdn Bhd. Ca-Al solid catalyst was prepared in-house by the Malaysian Palm Oil Board.

\subsection{Catalyst preparation and characterization}

The $\mathrm{Ca}-\mathrm{Al}$ catalyst system was prepared by coprecipitation technique at high supersaturation in a single container of two diluted solutions $\mathrm{A}$ and $\mathrm{B}$, in which solution A contained $\mathrm{Ca}^{2+}(67 \mathrm{~g})$ and $\mathrm{Al}^{3+}(150 \mathrm{~g})$ dissolved in $1 \mathrm{~L}$ deionized water. Solution $\mathrm{B}$ acting as precipitating reagents was prepared by dissolving $\mathrm{Na}_{2} \mathrm{CO}_{3}(42.4 \mathrm{~g})$ and $\mathrm{NaOH}(16 \mathrm{~g})$ in $0.5 \mathrm{~L}$ deionized water. The prepared solutions $\mathrm{A}$ and $\mathrm{B}$ were then mixed with high supersaturation technique for $18 \mathrm{~h}$ at $80{ }^{\circ} \mathrm{C}$ with vigorous stirring. Finally, the precipitate was filtered, washed with deoinized water up to $\mathrm{pH} 7$ and dried at $120{ }^{\circ} \mathrm{C}$ for overnight. The morphology of $\mathrm{Ca}-\mathrm{Al}$ was examined by scanning electron microscopy (SEM) using FEI Quanta 200 modal. The X-ray diffraction (XRD) pattern and textural properties of $\mathrm{Ca}-\mathrm{Al}$ such as specific surface area, pore volume and mean pore size were determined in the previous work [11].

\subsection{Transesterification reaction}

The process was performed in a $500 \mathrm{ml}$ reaction flask equipped with magnetic stirrer, vacuum line and a heating jacket. The reactants with mole ratio of 1.8,1 (methyl palmitate, triethanolamine) were mixed and heated to the desired reaction temperature and vacuum for two hours. When the reaction was completed, $\mathrm{Ca}-\mathrm{Al}$ solid catalyst was separated via vacuum filtration and the product was then analyzed using gas chromatography. For reusability study of $\mathrm{Ca}-\mathrm{Al}$, several reactions were performed under the optimum operating conditions by recycling $\mathrm{Ca}-\mathrm{Al}$ from one cycle to the subsequent cycle without washing or drying the catalyst cake after its separation from the reaction mixture.

\subsection{Analytical method}

Percent conversion of methyl palmitate and compositions of mono, di and tri-esteramine were determined via gas chromatography, performed using the capillary column ZB5HT inferno $(12 \mathrm{~m} \times 530 \mu \mathrm{m} \times 15 \mu \mathrm{m})$. The oven temperature was set initially at $100{ }^{\circ} \mathrm{C}$, held for $3 \mathrm{~min}$, and then increased at $6^{\circ} \mathrm{C} / \mathrm{min}$ to $350{ }^{\circ} \mathrm{C}$. Helium was used as the carrier gas at a flow rate of $20 \mathrm{~mL} / \mathrm{min}$. Injector temperature was set at $350{ }^{\circ} \mathrm{C}$ with split ratio set at 10,1 . Flame Ionization Detector (FID) was used and temperature was set at $360{ }^{\circ} \mathrm{C}$.

\subsection{Design of experiments and optimization method}

Design-Expert software (version 8) was employed in design the experimental works and optimizing the operating conditions. The experimental design was a three-level facecentered cube design involving 30 experiments. Facecentered design is usually used in order to avoid the experimental regions over the process limit [16]. Reaction temperature, vacuum, agitator speed and catalyst dosage were chosen as the independent variables while the conversion of methyl palmitate to esteramine was chosen as the response for the optimization study. These independent variables were studied at three levels with 6 replications of central point and 8 axial points. The value of alpha $(\alpha)$ was set at 1 .The actual and coded levels of each variables are shown in Table 1 . The selection of each variable was chosen based on various 
literatures reported on the application of heterogeneous catalysis for transesterification reaction. The maximum temperature studied was $170{ }^{\circ} \mathrm{C}$ as the boiling point of methyl palmitate reported is at $180{ }^{\circ} \mathrm{C}$ under maximum vacuum of 10 mbar [17]. The lower level of temperature was $130{ }^{\circ} \mathrm{C}$ as lower than that, the reaction rate was very slow. The range of vacuum supplied was studied based on the levels reported in previous study [11]. Maximum catalyst dosage of 1\% was chosen based on the results reported on the use of solid acid catalyst to produce the esteramine [9].

Table 1. Actual and coded levels of independent variables

\begin{tabular}{lllll}
\hline \multirow{2}{*}{ Independent variable } & \multirow{3}{*}{ Unit } & \multicolumn{3}{c}{ Variation levels } \\
\cline { 3 - 5 } & & $(-1)$ & $(0)$ & $(+1)$ \\
& & & & \\
\hline Temperature (A) & $\left({ }^{\circ} \mathrm{C}\right)$ & 130 & 150 & 170 \\
Vacuum (B) & $(\mathrm{mbar})$ & 500 & 255 & 10 \\
Catalyst Dosage (C) & $(\%)$ & 0.1 & 0.55 & 1.0 \\
Agitator Speed (D) & $(\mathrm{rpm})$ & 150 & 200 & 250 \\
\hline
\end{tabular}

\section{RESULTS AND DISCUSSION}

\subsection{Catalyst characterization}

SEM techniques was used to investigate the morphology of $\mathrm{Ca}-\mathrm{Al}$ solid catalyst employed in the reaction. The image shown in Figure 1 clearly indicates that $\mathrm{Ca}-\mathrm{Al}$ particles exhibit hexagonal shape. However, needle shape forms are also observed. The morphology of $\mathrm{Ca}-\mathrm{Al}$ obtained from the SEM technique is similar to the solid catalyst reported in the literatures [18].

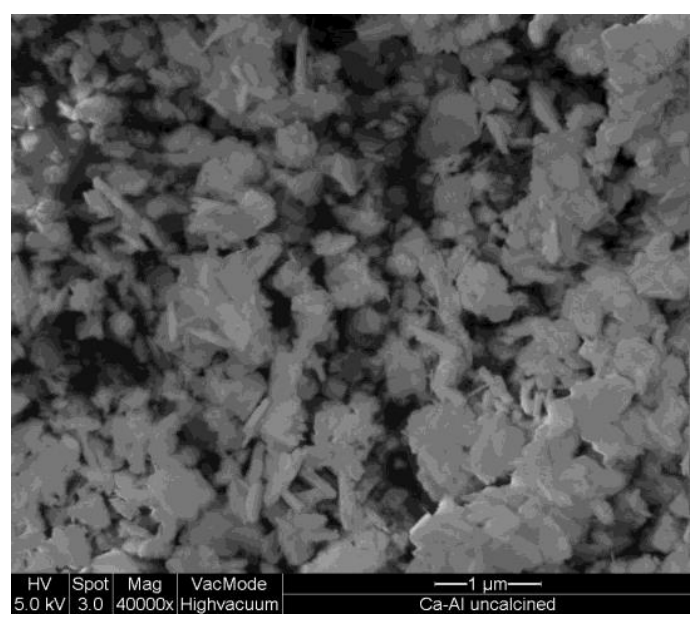

Figure 1. SEM image of Ca-Al

\subsection{Data analysis}

Face - centered design matrix represents in terms of coded value and the experimental results of conversion of methyl palmitate are tabulated in Table 2. A quadratic polynomial model was obtained based on the experimental data and this model was used to describe the mathematical relationship between the independent variables and dependent response. The following equation (1) and (2) in the terms of coded and actual factors were generated to predict the conversion of methyl palmitate into fatty esteramine,

Equation in terms of coded independent variables, conversion of methyl palmitate $(\%)=$

$75.07+24.72 * \mathrm{~A}+15.52 * \mathrm{~B}+20.48 * \mathrm{C}+8.72 * \mathrm{BC}-26.73 * \mathrm{C}^{2}(1)$ where $\mathrm{A}$, temperature, $\mathrm{B}$, vacuum, $\mathrm{C}$, catalyst dosage, $\mathrm{BC}$, interaction between vacuum and catalyst dosage and $\mathrm{C}^{2}$, quadratic effect of catalyst dosage.

Equation in terms of actual independent variables, conversion of methyl palmitate $(\%)=$

$-170+1.24 *$ Temperature $+0.02 *$ Vacuum $+210.8 *$ Catalyst Dosage $+0.08 *$ Vacuum*Catalyst Dosage

- $132 *$ Catalyst Dosage ${ }^{2}$

Table 2. Face-centered design matrix

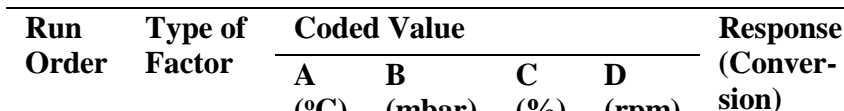

$\left({ }^{\circ} \mathrm{C}\right) \quad($ mbar $) \quad(\%) \quad($ rpm $)$ sion

\begin{tabular}{|c|c|c|c|c|c|c|}
\hline & & & & & & \\
\hline 5 & Center & 0 & 0 & 0 & 0 & 71.00 \\
\hline 6 & Center & 0 & 0 & 0 & 0 & 83.84 \\
\hline 11 & Center & 0 & 0 & 0 & 0 & 83.19 \\
\hline 13 & Center & 0 & 0 & 0 & 0 & 70.35 \\
\hline 20 & Center & 0 & 0 & 0 & 0 & 86.09 \\
\hline 21 & Center & 0 & 0 & 0 & 0 & 91.53 \\
\hline 7 & Axial & 0 & 0 & 1 & 0 & 65.78 \\
\hline 14 & Axial & 0 & -1 & 0 & 0 & 59.27 \\
\hline 16 & Axial & 1 & 0 & 0 & 0 & 93.60 \\
\hline 17 & Axial & -1 & 0 & 0 & 0 & 10.35 \\
\hline 22 & Axial & 0 & 0 & -1 & 0 & 15.49 \\
\hline 25 & Axial & 0 & 0 & 0 & -1 & 76.92 \\
\hline 26 & Axial & 0 & 0 & 0 & -1 & 81.55 \\
\hline 28 & Axial & 0 & 1 & 0 & 0 & 93.67 \\
\hline 1 & Factorial & 1 & -1 & -1 & 1 & 32.12 \\
\hline 2 & Factorial & 1 & -1 & 1 & -1 & 71.74 \\
\hline 3 & Factorial & -1 & -1 & 1 & -1 & 10.15 \\
\hline 4 & Factorial & -1 & -1 & -1 & -1 & 6.50 \\
\hline 8 & Factorial & -1 & 1 & 1 & 1 & 89.25 \\
\hline 9 & Factorial & 1 & -1 & 1 & 1 & 86.81 \\
\hline 10 & Factorial & -1 & 1 & -1 & 1 & 4.00 \\
\hline 12 & Factorial & 1 & -1 & -1 & -1 & 49.67 \\
\hline 15 & Factorial & 1 & 1 & -1 & 1 & 58.69 \\
\hline 18 & Factorial & 1 & 1 & -1 & -1 & 79.35 \\
\hline 19 & Factorial & -1 & 1 & -1 & -1 & 2.00 \\
\hline 23 & Factorial & 1 & 1 & 1 & -1 & 98.23 \\
\hline 24 & Factorial & 1 & 1 & 1 & 1 & 98.70 \\
\hline 27 & Factorial & -1 & -1 & 1 & 1 & 12.00 \\
\hline 29 & Factorial & -1 & 1 & 1 & -1 & 86.72 \\
\hline 30 & Factorial & -1 & -1 & -1 & 1 & 3.00 \\
\hline
\end{tabular}

Note: A, temperature; B, vacuum; C, catalyst dosage; D, agitator speed

Statistical analysis of variance (ANOVA) was performed to investigate the significance and fitness of the model as well as the effects of the individual independent variables and their interaction on the response. From the ANOVA analysis shown in Table 3, it can be observed that the model is significant as the $p$-value (probability of error value) for the model is less than 0.0001 to predict the conversion of methyl palmitate. The lack of fit p-value of 0.0815 (lack of fit $\mathrm{p}$ value $>0.05$ is not significant) implies that the model is fitted 
to all data (not significant lack of fit is good). In this study, temperature, $\mathrm{A}$, vacuum, $\mathrm{B}$ and catalyst dosage, $\mathrm{C}$, interaction of vacuum - catalyst dosage, $\mathrm{BC}$ and quadratic effect of catalyst dosage, $\mathrm{C}^{2}$ are significant model terms with $p$-value less than 0.05 ( $p$-value $<0.05$ indicates that the model terms are significant) for $95 \%$ confidence interval. Based on the Fvalue of the significant model terms, temperature had the largest effect on conversion of methyl palmitate. The ranking of the significance terms is as follow; temperature > catalyst dosage > quadratic effect of catalyst dosage > vacuum > interaction of vacuum and catalyst dosage. Agitator speed, D, interactions of temperature - vacuum, $\mathrm{AB}$, temperature catalyst dosage, AC, and temperature - agitator speed, $\mathrm{AD}$, quadratic effect of temperature, $\mathrm{A}^{2}$, vacuum, $\mathrm{B}^{2}$ and agitator speed, $\mathrm{D}^{2}$ were found to be insignificant model terms and thus these terms were excluded in order to improve the model and optimization results. The value of R-squared of 0.8476 indicates that the model fits the experimental data, because according to reported works, value of $\mathrm{R}^{2}>0.75$ indicates fitness of the model $[19,20]$. Predicted R-squared of 0.7478 is in agreement with the adjusted R-squared of 0.8158 as the adjusted and predicted R-squared values are within 0.2 of each other. This confirms the precision of the experimental data and model [21]. Adequate precision measures the signal to noise ratio and a value greater than 4 is desirable. Result shows that the adequate precision value was 18.781, indicating that the model can be used to navigate the design space. Figure 2 shows the plot of predicted versus actual conversion of methyl palmitate $(\%)$, which verified that the predicted response (conversion, \%) is in agreement with the observed data (actual) in the range of the operating conditions. The value $\mathrm{R}^{2}=0.8476$ indicated that the model fits the experimental data.

Table 3. ANOVA results for the model and model terms

\begin{tabular}{lccc}
\hline Source & F-value & $\begin{array}{c}\mathrm{p} \text {-value, } \\
\text { Prob }>\mathrm{F}\end{array}$ & \\
\hline Model & 26.96 & $<0.0001$ & Significant \\
A-temperature & 50.20 & $<0.0001$ & \\
B-vacuum & 19.79 & 0.0002 & \\
C-catalyst & 34.45 & $<0.0001$ & \\
dosage & & & \\
BC & 5.55 & 0.0270 & \\
C $^{2}$ & 23.48 & $<0.0001$ & \\
Lack of fit & 3.58 & 0.0815 & not significant \\
\hline
\end{tabular}

R-squared $=0.8476$, Adjusted R-squared $=0.8158$, Predicted R-squared $=$ 0.7478 , Adequate Precision $=18.344$

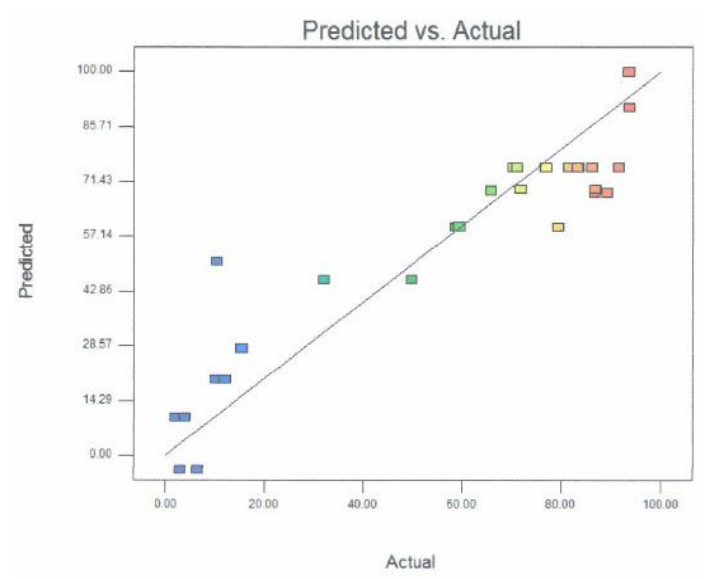

Figure 2. Scatter plot of predicted methyl palmitate conversion (\%) against actual methyl palmitate conversion (\%)

\subsection{Influence of process parameters on conversion of methyl palmitate}

The interaction between vacuum and catalyst dosage and their effect on conversion of methyl palmitate is illustrated in the response surface 3D plot as shown in Figure 3, generated based on equation (1) and by having the temperature and agitator speed at their center points. The response surface indicates that at low vacuum, the conversion increase with an increase in catalyst dosage. However, higher catalyst dosage leads to a slight reduction in the conversion, due to the fact that the quadratic term of the catalyst dosage is more significant with a negative effect (equation 1). Considerable increment in conversion of methyl palmitate was observed with increasing catalyst dosage at higher vacuum. This is due to the fact that the interaction term of vacuum - catalyst dosage, $\mathrm{BC}$, is more significant with a positive effect on the response (equation 1).

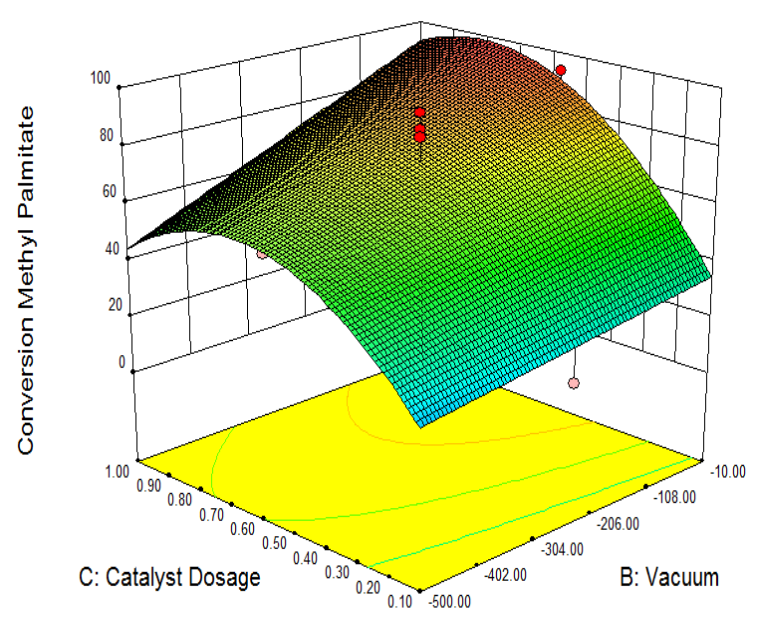

Figure 3. Response surface 3D plot of conversion of methyl palmitate versus catalyst dosage and vacuum at temperature of $150{ }^{\circ} \mathrm{C}$ and agitator speed of $200 \mathrm{rpm}$

\subsection{Optimization of operating conditions and validation of model}

In order to determine the optimum levels of each process variables for maximum conversion of methyl palmitate, contour plots were constructed by plotting the response (conversion of methyl palmitate) against any two independent variables, while maintaining the third variable at their center points.

Contour plots of the predicted conversion of methyl palmitate as a function of two independent variables; (a) temperature and vacuum, (b) temperature and catalyst dosage (c) vacuum and catalyst dosage are demonstrated in Figure 4(a) - (c). Contour plot of conversion of methyl palmitate versus temperature and vacuum shown in Figure 4(a) at fixed catalyst dosage of $0.55 \%$ and agitator speed of $200 \mathrm{rpm}$ reveals that generally, increase in both variables resulted in an increase in conversion. However, conversion of methyl palmitate was more affected by temperature compared to vacuum. Temperature gave a profound impact on transesterification, in which the rate of reaction increases as the tempernturs is innreased. Higher conversion was obtained at higher $\mathrm{R}^{2}=0.8476$ rom 150 to $170{ }^{\circ} \mathrm{C}$ and higher vacuum from 150 to 10 mbar. 
Figure 4(b) demonstrates the plot of conversion of methyl palmitate versus temperature and catalyst dosage with vacuum fixed at $255 \mathrm{mbar}$ and agitator speed of $200 \mathrm{rpm}$. It was observed from the figure that minimal conversion of methyl palmitate was obtained at low temperature and low amount of catalyst dosage. An increase in temperature resulted in an increase in conversion and it appeared that the conversion of methyl palmitate increased with increase in catalyst dosage from 0.5 to $0.8 \%$. When the catalyst dosage was increased beyond $0.8 \%$, a reduction in the conversion was experienced, presumely due to increase in viscosity of the reaction mixture when higher amount of $\mathrm{Ca}-\mathrm{Al}$ catalyst was incorporated. This will reduce the external mass transfer rates between bulk phases of the reactants towards the surface of the solid catalyst. This finding is in agreement with several published works reporting similar trend on the effect of catalyst dosage [22]. It was also reported in the biodiesel production from Styrax confuses Hemsl seed oil, in which the yield started to reduce when the magnetic solid acid catalyst concentration was more than $5 \mathrm{~g} / \mathrm{l}$. The higher amount of catalyst could result in agglomeration and settled out from reaction mixture and thus, reduce the catalyst surface area [23]. Other previous work described that the percentage of conversion was increased by increasing the catalyst dosage from 3.0 to $5.8 \%$ and decreased with further increase to $7 \%$ in the enzymatic synthesis of esteramine using lipase. Unlike heterogeneous transesterification, higher reaction temperatures were reported to induce the inactivation of the enzyme used in the study [7].

The plot of conversion of methyl palmitate versus vacuum and catalyst dosage at fixed temperature $150{ }^{\circ} \mathrm{C}$ and agitator speed of $200 \mathrm{rpm}$ is demonstrated in Figure 4 (c). It was found that the conversion was more affected by the catalyst dosage than vacuum. Increase in catalyst dosage resulted in an increase in conversion until it reached $0.8 \%$, whereas, an increase in vacuum did not significantly increase the conversion of methyl palmitate. High vacuum of 10 mbar gave maximum conversion when the catalyst dosage was at $0.78 \%$, suggesting that an efficient methanol removal system favored the conversion of methyl palmitate into esteramine. Lower conversion was observed at vacuum lower than 200 mbar when $0.78 \%$ catalyst dosage was incorporated, presumely due to insufficient energy to pull the methanol away from the system. The excessive accumulation of methanol could lead to higher decomposition of esteramine into methyl palmitate, hence resulting in a higher percentage of unconverted methyl palmitate.

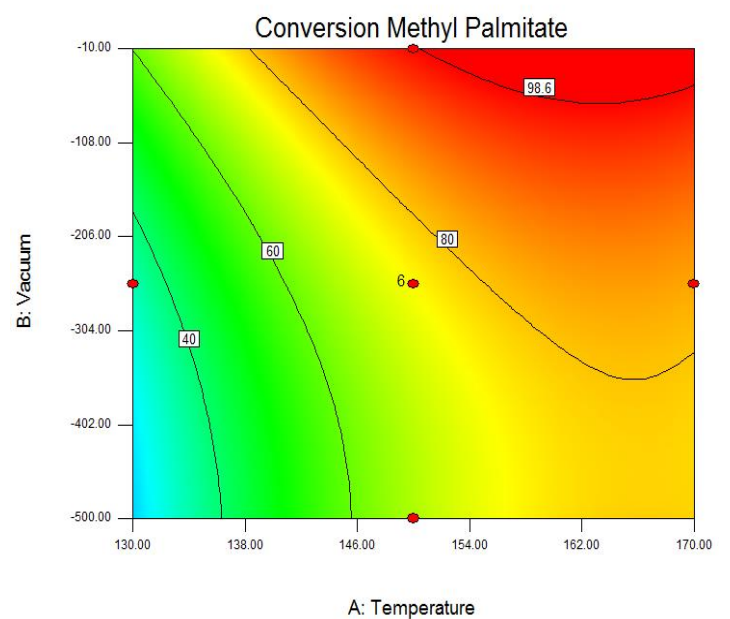

(a)

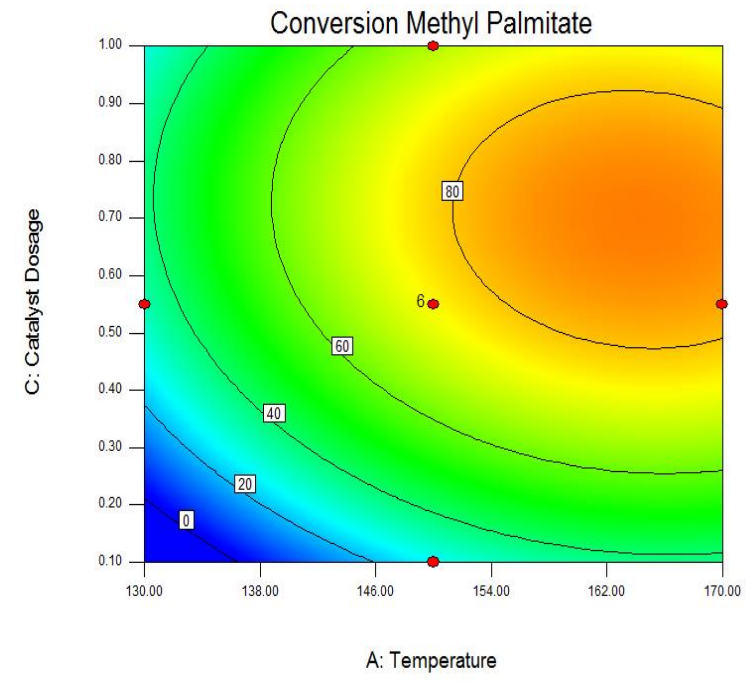

(b)

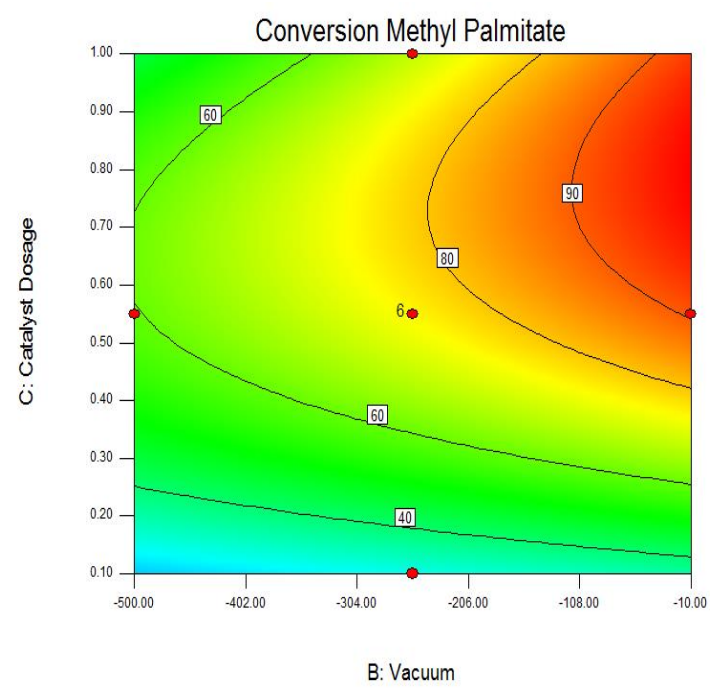

(c)

Figure 4. (a) Contour plot of

conversion of methyl palmitate versus temperature and vacuum at catalyst dosage of $0.55 \%$ and agitator speed of $200 \mathrm{rpm}$. (b) Contour plot of conversion of methyl palmitate versus temperature and catalyst dosage at vacuum of 255 mbar and agitator speed of $200 \mathrm{rpm}$. (c) Contour plot of conversion of methyl palmitate versus vacuum and catalyst dosage at temperature of $150{ }^{\circ} \mathrm{C}$ and agitator speed of 200 rpm.

For optimization, the transesterification reaction was performed under the recommended conditions and the experimental results were compared with predicted values. The optimum operating conditions calculated by using the numerical optimization method were temperature of $169.4^{\circ} \mathrm{C}$, vacuum of 299 mbar, catalyst dosage of $0.78 \%$ and agitator speed of $200 \mathrm{rpm}$ as shown in Table 4. The conversion of methyl palmitate under the optimum reaction conditions was predicted to be $99 \%$. It was found that the experimental conversion obtained was $96 \%$, which was $97 \%$ in agreement with the predicted value. Therefore, this implies that the generated quadratic model derived from RSM experimental design has sufficient accuracy to predict the conversion of methyl palmitate. The reaction performed under this optimum condition yielded $21 \%$ mono, $45 \%$ di and $27 \%$ triesteramine. 
The optimum operating conditions obtained from RSM were compared with the one-factor-at-a-time (OFAT) experimental approach. The optimum temperature obtained from RSM was found to be similar to that of manual OFAT technique of appoximately $170{ }^{\circ} \mathrm{C}$. Slightly higher optimum value of $\mathrm{Ca}-\mathrm{Al}$ dosage of about $0.78 \%$ was obtained from
RSM compared to $0.5 \%$ from OFAT approach. However, $0.78 \%$ of $\mathrm{Ca}-\mathrm{Al}$ dosage was acceptable as it was lower than the maximum solid catalyst dosage of $1 \%$ employed in esteramine production via esterification of stearic acid and triethanolamine reported in literatures [8-10].

Table 4. Optimum operating conditions and conversion of methyl palmitate using RSM

\begin{tabular}{|c|c|c|c|c|c|}
\hline \multirow[t]{2}{*}{ Temperature $\left({ }^{\circ} \mathrm{C}\right)$} & \multirow{2}{*}{$\begin{array}{l}\text { Vacuum } \\
\text { (mbar) }\end{array}$} & \multirow{2}{*}{$\begin{array}{c}\text { Catalyst } \\
\text { Dosage }(\%)\end{array}$} & \multirow{2}{*}{$\begin{array}{c}\text { Agitator } \\
\text { Speed (rpm) }\end{array}$} & \multicolumn{2}{|c|}{ Conversion of methyl palmitate } \\
\hline & & & & Experimental & Predicted \\
\hline 169.4 & 299 & 0.78 & 200 & $96.0^{*}$ & 99.0 \\
\hline
\end{tabular}

Significant difference on vacuum level was observed between RSM and manual OFAT optimization process, where lower vacuum of about 299 mbar was established via RSM and 10 mbar obtained from manual optimization. Performing the transesterification at 299 mbar is more cost effective than conducting the process at high vacuum of 10 mbar as it can save a considerable amount of energy especially for industrial application. Overall, optimization process using RSM technique demonstrated a similar conversion and fatty esteramine composition with the OFAT approach. Although the tri-esteramine content obtained from RSM optimization was $27 \%$, which was slightly higher than $25 \%$ for experiencing a better fabric softening formulation stability [ 24], this might be overcome by performing the reaction at mole ratio lower than 1.8,1 (methyl palmitate, triethanolamine) or employing solid catalyst with suitable pore diameters. According to literatures, suitable pore diameters of catalyst could improve selectivity to mono and di-esteramine and minimize tri-esteramine content [8-10].

\subsection{Reusability of catalyst}

In conventional process, sodium methoxide was commonly used as the catalyst for transesterification of methyl ester and triethanolamine. However, the catalyst was difficult to be separated from the product and could not be reused. Reusability is an important property for heterogeneous catalyst as it can reduce production cost. As illustrated in Figure 5, conversion and fatty esteramine compositions were sustained for three cycles. However, in the fourth cycle, conversion was reduced and fatty esteramine compositions seemed to change significantly. Hence, $\mathrm{Ca}-\mathrm{Al}$ can be reused for three subsequent cycles in the production of fatty esteramine via transesterification of palm-based methyl palmitate and triethanolamine. The reusability of $\mathrm{Ca}-\mathrm{Al}$ catalyst and the optimum operating conditions obtained in this study were compared with reported reusability study of other solid catalyst in transesterification processes. Transesterification of palm oil for biodiesel production using $\mathrm{CaO} / \mathrm{Al}_{2} \mathrm{O}_{3}$ reported that the catalyst was reused for only two subsequent cycles at optimum condition of $65{ }^{\circ} \mathrm{C}$, catalyst content of 6 wt.\% and alcohol/oil molar ratio of 12,1 [25]. Meanwhile, $\mathrm{CaO}$ catalyst employed in the production of glycerol carbonate via transesterification of glycerol and dimethyl carbonate showed a weak catalytic activity in the second cycle of the reaction conducted at $95{ }^{\circ} \mathrm{C}$, catalyst/glycerol molar ratio $=0.06$ and dimethyl carbonate/glycerol molar ratio $=3.5$ [26] .

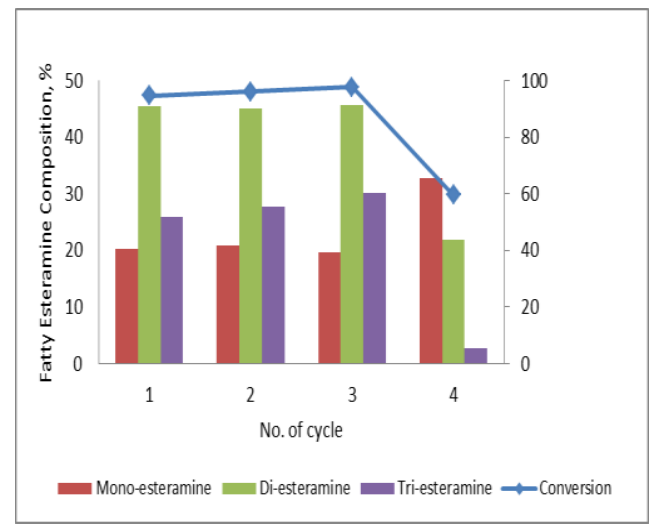

Figure 5. Reusability of $\mathrm{Ca}-\mathrm{Al}$. (Optimum reaction conditions, $169^{\circ} \mathrm{C}, 299$ mbar, mole ratio of $1.8,1$ (methyl palmitate,triethanolamine), $200 \mathrm{rpm}$ and $0.78 \%$ catalyst dosage)

\section{CONCLUSION}

The statistical analysis from ANOVA revealed that the individual effects of temperature, catalyst dosage and vacuum on conversion of methyl palmitate were significantly observed whereas, agitator speed exhibited insignificant influence. The interaction between vacuum and catalyst dosage gave significant effect on conversion. The optimum conditions were established at $169{ }^{\circ} \mathrm{C}, 299$ mbar, $0.78 \%$ catalyst dosage and agitator speed of $200 \mathrm{rpm}$. Experimental conversion obtained was $96 \%$, which was in good agreement with the predicted value of $99 \%$. Quadratic model generated can be used to predict the conversion of methyl palmitate accurately. The catalyst was reusable and the conversions as well as fatty esteramine compositions were sustained for three subsequent cycles.

\section{ACKNOWLEDGEMENT}

The author acknowledged the financial support by the Malaysian Palm Oil Board. This work was carried in collaboration with the Center for Separation Science and Technology (CSST) of University of Malaya.

\section{REFERENCES}

[1] Friedli F., Keys R., Toney C.J., Portwood O., Whittlinger D., Doerr M. (2001). Novel new ester 
quaternaries for improved performance benefits as rinse cycle fabric softeners, J. Surfact. Deterg, Vol. 30, pp. 401-405.

[2] Tyagi R., Tyagi V.K., Khanna R.K. (2006). Synthesis, characterization and performance of tallow fatty acids and triethanolamine based esterquats, J.Oleo Sci, Vol. 55, pp. 337-345.

[3] Puchta R., Krings P., Sandkuehler P. (1993). A new generation of softeners, Tenside, Surfact. Deterg, Vol. 30, pp. 186-191.

[4] Jiang Y., Geng T., Li Q. (2012). Synthesis of stearic acid triethanolamine ester over Al-SBA-J0, Porous Mater, Vol. 19, pp. 369 -374.

[5] Idris Z., Ahmad S., Nakasato S. (1995). Preparation of palm-based esteramine using chemical catalyst, Elaies, Vol. 7, No. 2, pp. 135 -145.

[6] Haliza A.A., Idrisol Z., Hazimah A.H. (2014), Transesterification of palm stearin methyl ester and triethanolamine, An Alternative Technology for Esterquats Production. Inter J App Sci and Tech, Vol. 4, No. 7, pp. 60-66.

[7] Masoumi H.R.F., Kassim A., Basri M., Abdullah D.K., Abdollahi Y., Ghani S.S., Rezaee M. (2013). Statistical optimization of process parameters for lipase-catalyzed synthesis of triethanolamine-based esterquats using response surface methodology in 2liter bioreactor, The Sci World Journal, pp. 1-9.

[8] Geng T., Li Q., Jiang Y., Wang W. (2010). Synthesis of stearic acid triethanolamine ester over solid acid catalysts, Chinese Ch,em Lett 21, pp. 1020-1024.

[9] Geng T., Li Q., Jiang Y., Wang W. (2011). Esterification of stearic acid with triethanolamine over zirconium sulfate supported on SBA-15 mesoporous molecular sieve, J. Surfact Deterg, Vol. 14, No. 1, pp. 15-22.

[10] Jiang Y., Geng T., Li Q. (2012). Synthesis of stearic acid triethanolamine ester over Al-SBA-15, J Porous Mater 19, pp. 369-374.

[11] Haliza A.A., Aroua M.K., Yusoff R., Abas N.A., Idris Z., Hazimah A.H. (2016). Production of palm-based esteramine through heterogeneous catalysis, J Surfact Deterg, Vol. 19, No. 1, pp. 11-18.

[12] Cavani F., Trifirb F., Vaccari A. (1991). Hydrotalcitetype anionic clays preparation, properties and applications, Catal Today, Vol. 11, No. 2, pp. 173-301.

[13] Simonetti E.A.N., Thim G.P., Cortez G.G. (2014). Ca$\mathrm{Al}$ hydrotalcites as catalysts for methanolysis and ethanolysis of soybean oil, Mod Res Catal, Vol. 3, pp. $117-127$.

[14] Gao L.J., Teng G.Y., Xiao G.M., Wei R.P. (2010). Biodiesel from palm oil via loading $\mathrm{KF} / \mathrm{Ca}-\mathrm{Al}$ hydrotalcite catalyst, Biomass Bioenerg, Vol. 34, pp. 1283-1288.
[15] Moos W.H., Pavia M.R., Ellington A.D., Kay B.K. (1997). Annual Reports in Combinatorial Chemistry and Molecular Diversity,Vol. 1, The Netherlands, ESCOM Science Publishers B.V.

[16] Norhazimah A.H., Faizal C.K.M. (2012). Optimization of fermentation parameters for the production of bio-ethanol from oil palm trunks sap using face-centered (CCD), Australian and New Zealand Chemical Engineers Conference Proceeding (Chemeca).

[17] Bonhorst C.W., Althouse P.M., Triebold H.O. (1948). Esters of naturally occurring fatty acids, Ind Eng Chem, Vol. 40, pp. $2379-84$.

[18] Savita G.D., Agarwal D., Susanta B. (2008). Synthesis and characterization of hydrotalcites: potential thermal stabilizer for PVC, Indian J Chem 47A, pp. 1004-1008.

[19] Reddy L.V.A., Wee Y.J., Yun J.S., Ryu H.W. (2008). Optimization of alkaline protease production by batch culture of Bacilus sp. RKY3 through Plackett-Burman and response surface methodological approaches, Bioresource Technology, Vol. 99, No. 7, pp. 22422249.

[20] Haaland P.D. (1989). Experimental design in biotechnology, New York, Marcel Dekker Inc.

[21] Zabeti M., Daud W.M.A.W., Aroua M.K. (2009). Optimization of the activity of $\mathrm{CaO} / \mathrm{Al}_{2} \mathrm{O}_{3}$ catalyst for biodiesel production using response surface methodology, Appl Cataly A Gen, Vol. 366, pp. 154159.

[22] Xie W., Yang X., Zang X. (2015). Interesterification of soybean oil methyl stearate catalyzed by guanidinefunctionalized SBA - 15 silica, J Am Oil Chem Soc, Vol. 92, pp. 915 - 925.

[23] Wang Y., Nie X., Liu Z. (2015). Biodiesel synthesis from styrax confuses hemsl catalyzed by $\mathrm{S}_{2} \mathrm{O}_{8}^{2-1} \mathrm{ZrO}_{2}$ - $\mathrm{TiO}_{2}-\mathrm{Fe}_{3} \mathrm{O}_{4}, J$ Am Oil Chem Soc, Vol. 92, pp. 813 -820 .

[24] Franklin R., Mendello R., Albert P., Steichen D., Trinh P.N. (2002). High di (alkyl fatty ester) amines and quaternary ammonium compounds derived therefrom, Patent No. US 20020025915 A1.

[25] Zabeti M., Daud W.M.A.W., Aroua M.K. (2010). Biodisel production using alumina-supported calcium oxide: an optimization study, Fuel Process Tecnol, Vol. 91, pp. 243-248.

[26] Jose R.O., Olga G., Belen M., Amaia P., Camilo R., Leire L., Jesus T., Marra C.V. (2009). Synthesis of glycerol carbonate from glycerol and dimethyl carbonate by transesterification: catalyst screening and reaction optimization, Appl Cataly A Gen, Vol. 366, pp. 315-324. 